Struttura di missione per la Commemorazione del centenario della Prima guerra mondiale Presidenza del Consiglio dei Ministri

Comune di Bibbiano - Bibbiano "La Culla" Provincia di Reggio Emilia
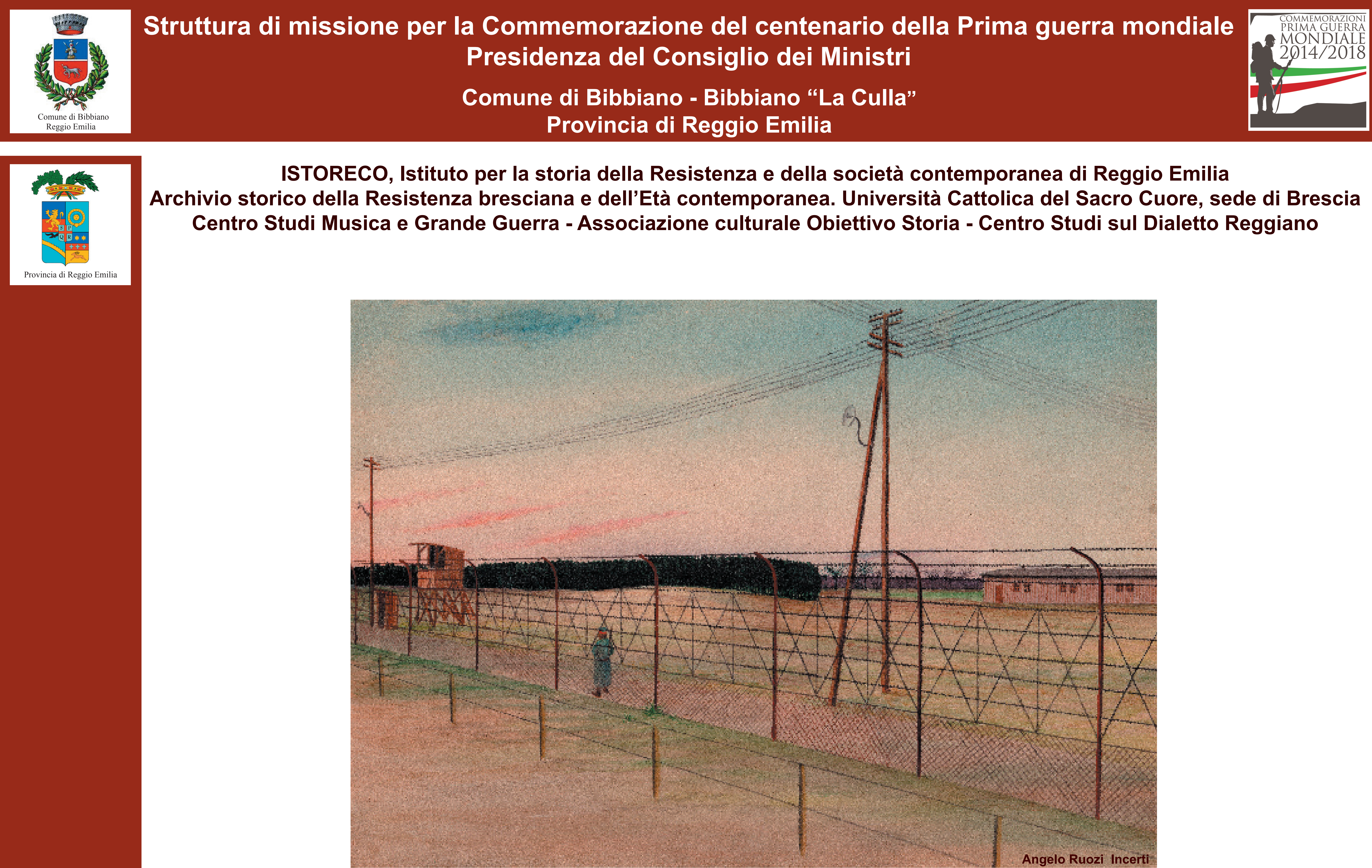

Nessun campo di battaglia è cosi disperatamente tragico come un esercito in ritirata od una colonna di prigionieri affamati ed abbandonati a se stessi. I morti, per quanto dilaniati, sono di qualcuno, sono almeno della nostra pietà; i prigionieri non sono di nessuno, nemmeno del nemico.

Angelo Rognon

\title{
PRIGIONIERI DIMENTICATI italiani nei lager della grande guerra
}

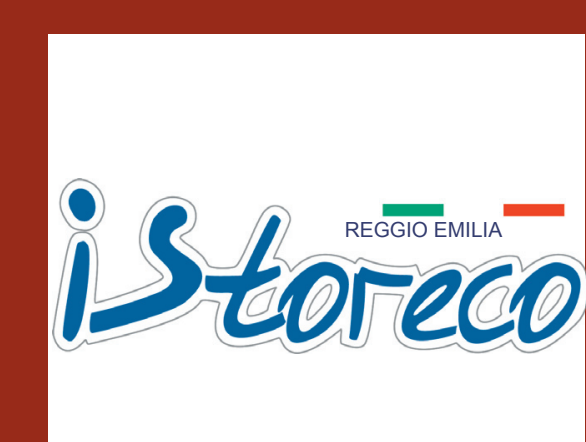

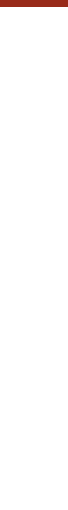

\section{西}

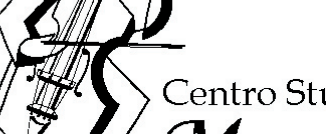

Musica

3
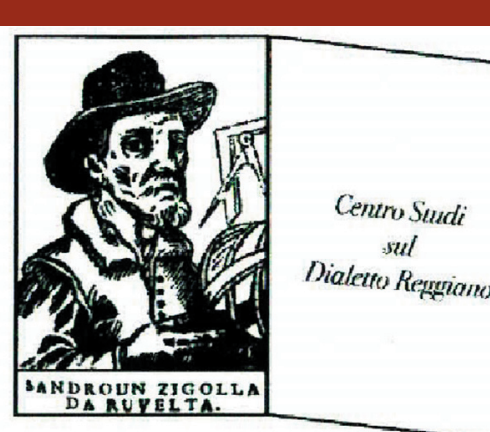

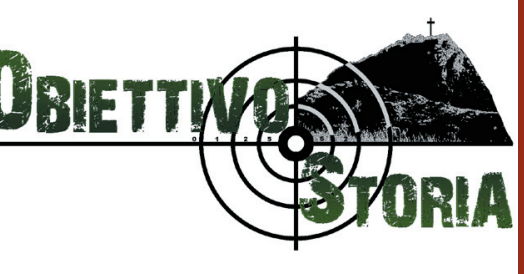
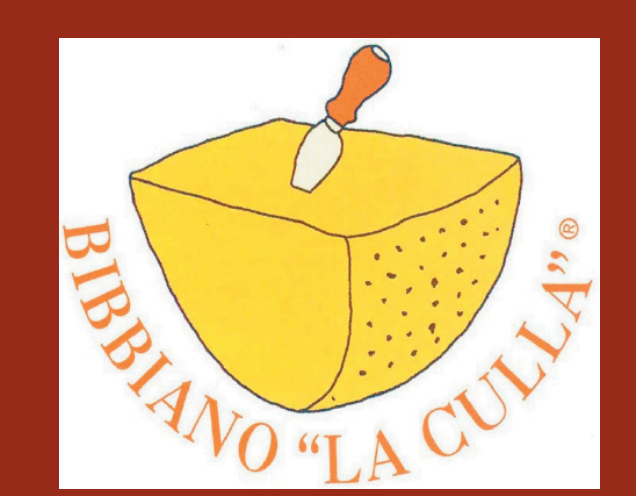

da un'idea di Lauro James Garimberti e Carlo Perucchetti

\section{MOSTRA}

$14-29$ settembre 2013 (ingresso libero)

Bibbiano (Reggio Emilia) Sala polivalente del Teatro Metropolis, via Gramsci 4

Inaugurazione della mostra sabato 14 settembre ore 10,30.

sabato e domenica 14-15 settembre apertura continuata

da martedì a venerdi 20,30-22,30. Sabati e domeniche 21 e $22-28$ e 29 settembre $15-19$ e 20,30-22,30

Prenotazioni per visite guidate di gruppi e scolaresche

Domenica 15 settembre, ore 21, Teatro Metropolis (ingresso libero)

Lunedì 16 settembre, ore 21, Teatro Metropolis (ingresso libero)

\section{SPETTACOLO TEATRALE}

PER LA PIU' GRANDE ITALIA ovvero SANDRONE SOLDATO

commedia scritta nei lager di Rastatt e Celle (1917-18) da Angelo Ruozi Incerti

compagnia teatrale I PAZZI DI PIAZZA, regia di AURO FRANZONI con MATTEO BARTOLI

Durante la serata sarà presentata la pubblicazione PER LA PIU' GRANDE ITALIA ovvero SANDRONE SOLDATO, edita da REGGIOSTORIA

\section{Martedi 17 settembre, ore 21, Teatro Metropolis (ingresso libero) CONCERTO}

\section{MUSICA DALLA PRIGIONIA}

Canti popolari e composizioni scritte da prigionieri a Rastatt, Cellelager e Mauthausen (1915-1918) SILVIA FELISETTI soprano, LUCA BODINI tenore, Ensemble strumentale MUSICA E GRANDE GUERRA 